\title{
LOS FLUJOS MIGRATORIOS ILEGALES EN EL ESTRECHO DE GIBRALTAR
}

\section{Jamal Benamar* \\ Francisco Alberto Vallejo Peña**}

\begin{abstract}
RESUMEN
Las migraciones constituyen un factor importante en los intercambios internacionales porque generan riqueza para ambas poblaciones de origen y de acogida. Para que sus efectos perversos desaparezcan hay que buscar como reducir entre todos los abismos existentes entre las economías de los países ricos y los de África. El efecto perverso de estos movimientos, la inmigración ilegal o clandestina, no es un fenómeno nuevo. Esta manera de emigrar fue tolerada por muchos países de destino, desde los años 50 hasta la crisis económica y la crisis del petróleo de los años 70. La permisividad se debía a una carencia en la regulación jurídica de los flujos migratorios (ausencia de leyes y de un control fronterizo estricto) que se justificaba por la necesidad de crecimiento de las economías europeas en un contexto de posguerra. Este artículo trata de valorar el fenómeno de las migraciones ilegales hoy día en el Estrecho de Gibraltar.
\end{abstract}

\section{PALABRAS CLAVE}

Flujos migratorios, inmigración y seguridad, inmigración y desarrollo, cultura de la inmigración, integración, espacio euro mediterráneo, globalización.

\begin{abstract}
The migrations constitute an important factor in the international interchanges because they generate wealth for both populations of origin and of reception. In order that his perverse effects disappear it is necessary to seek to reduce like between all the existing abysses between the economies of the rich countries and those of Africa. The perverse effect of these movements, the illegal or clandestine immigration, is not a new phenomenon. This way of emigrating was tolerated by many countries of destiny, from the 50s up to the economic crisis and the crisis of the oil of the 70s. The permissiveness owed a lack to itself in the juridical regulation of the migratory flows (absence of laws and of a frontier strict control) that was justifying itself for the need of growth of the European economies in a context of post-war period. This article tries to value the phenomenon of the illegal migrations today for the Strait of Gibraltar.
\end{abstract}

\section{KEY WORDS}

Migratory flows, immigration and safety, immigration and development, culture of the immigration, integration, spread Mediterranean euro, globalization.

\footnotetext{
* Profesor de Comunicación de la Universidad Abdelmalik Saadi en Tánger (Marruecos)

** Profesor de Sociología de la Universidad de Málaga
} 


\section{INTRODUCCIÓN}

Las llamadas migraciones irregulares, clandestinas o ilegales están tomando en este principio de Siglo XXI unas dimensiones inquietantes. Es un fenómeno mundial que afecta tanto a los países desarrollados, como Estados Unidos o los países de Europa Occidental, como a los países en vía de desarrollo: LatinoAmérica, donde países como Méjico o Argentina reciben un flujo de emigrantes procedentes de los países limítrofes, Asia que vive las tragedias de los llamados Boat People, y África que conoce un interrumpido flujo de migraciones debido a los incesantes conflictos entre países fronterizos.

Este fenómeno adquiere una singular importancia en el espacio mediterráneo donde la inmigración juega un papel muy importante en las relaciones interestatales de los países ribereños. Las migraciones clandestinas están adquiriendo una nueva dimensión alarmante, en la medida en que, por su naturaleza, los flujos migratorios con destino a los países de la Unión Europea enturbian a menudo las relaciones entre los países ribereños del Estrecho de Gibraltar y en particular entre España y Marruecos. Considerado al principio como un proyecto económico, la migración tiende hacia un proyecto de vida.

El análisis de esta cuestión exige una mejora en el conocimiento de las circunstancias en las que se producen los movimientos migratorios entre el Norte de Marruecos y el Sur de Andalucía: identificando, analizando y valorando las características y el proceso migratorio en el Estrecho de Gibraltar.

Desde una perspectiva de un análisis cualitativo ${ }^{1}$, pretendemos exponer a continuación aquellos aspectos especialmente relevantes del fenómeno de la inmigración irregular entre la frontera Sur de Europa (Andalucía Sur) y el Norte de África (Norte de Marruecos): la valoración del fenómeno de la inmigración, las características generales de los inmigrantes, la evolución reciente de los flujos migratorios y las posibles soluciones a la inmigración.

\section{VALORACIÓN DEL FENÓMENO DE LA INMIGRACIÓN}

Los inmigrantes están contribuyendo significativamente al crecimiento de las economías de los países europeos y también de los países de origen. La inmigración en España se ha disparado estos últimos diez años para alcanzar 3,7 millones en 2005, de los cuales casi una cuarta parte están en situación irregular. El Gobierno español procedió a regularizar cerca de 600000 trabajadores clandestinos, una medida muy criticada por Alemania y Francia.

Según fuentes informativas ${ }^{2}$, en España "más de la mitad del crecimiento del año 2006 es debido a los inmigrantes y aportan más que lo que reciben”. Otra noticia 
de una segunda fuente ${ }^{3}$ de información prevé una perdida de más de 20 millones de trabajadores en Europa de aquí al año 2030.

Por lo tanto, el hecho de que los flujos migratorios representan para los países europeos una fuente diversificada de riqueza ${ }^{4}$ (cultural, económica, social, demográfica), y una alternativa para las economías de los de origen, es toda una realidad.

En el 2003 las remesas representaron para Marruecos el 10\% del PIB según datos de la Oficina de Cambios marroquí y el 30\% del Comercio Exterior. Marruecos es uno de los países del mundo más dependientes de las remesas que recibe de sus emigrantes.

"Es indiscutible que la inmigración representa para España un factor socioeconómico importante. Suele ser muy cualificada (médicos, ingenieros,...) en menor proporción, o muy poco preparada en mayor proporción. A nivel de la demografía, la tasa de crecimiento de la población se ha incrementado gracias a la población de inmigrantes.

También está reconocido que la inmigración ha contribuido al crecimiento de afiliados a la seguridad social de manera importante. La población activa de origen no comunitario ronda los dos millones de trabajadores y representa un $9 \%$ del total de la población activa en España (era tan solo del 3\% en el año 2001).

"A nivel del núcleo familiar, la mujer española ha podido desempeñar una labor profesional gracias a la presencia de las mujeres inmigrantes empleadas del hogar para ocuparse de los hijos y de los familiares enfermos o incapacitados." D-9

El efecto perverso de estos movimientos, la inmigración ilegal o clandestina, no es un fenómeno nuevo. Esta manera de emigrar fue tolerada por muchos países de destino, desde los años 50 hasta la crisis económica y la crisis del petróleo de los años 70. La permisividad se debía una carencia en la regulación jurídica de los flujos migratorios (ausencia de leyes y de un control fronterizo estricto) que se justificaba por la necesidad de crecimiento de las economías europeas en un contexto de posguerra.

Durante las dos décadas que siguieron el "crack económico" de los 70, la presión migratoria era tal que obligo los países de acogida a tomar medidas destinadas a controlar esos flujos migratorios (visados, controles fronterizos mas severos, contratos de trabajo selectivos, leyes de extranjería,...). A pesar de esas restricciones el volumen global de los flujos siguió aumentado, porque a la inmigración ilegal fuertemente ralentizada se sumó la inmigración generada por las reagrupaciones familiares y los contratos temporales de trabajo.

"Hablando de España podemos confirmar que hacia diez años atrás las mafias de tráfico de personas que trabajan desde Marruecos y España tenían cómplices de los empresarios agrícolas españoles para mandarles gente de pateras que son una mano 
de obra barata que cobran el medio de los obreros españoles lo cual fomenta la economía sumergida que gozaba de una impunidad y amparo de algunas partes de las autoridades españoles." D-2

En la actualidad, la inmigración ilegal representa un gran problema para los países de acogida. Las restricciones y los controles destinados a desalentar a los candidatos en sus proyectos migratorios ha surtido el efecto contrario: se desarrollo la inmigración ilegal con destino a España e Italia principalmente utilizando las redes clandestinas que tomaron el relevo de los circuitos legales.

"Pensamos - desde pateras de la vida - que las mafias no resumen ni reflejan la verdadera realidad de la emigración ilegal pero creemos que las mafias es un resultado directo de las políticas sociales antidemocráticas y no populares de los países emisores de la emigración ilegal por una parte, y por otra parte resultado lógico de política de cierre de fronteras adoptada por los países potentes como Europa y América, además del reparto injusto de la riqueza a nivel mundial.” D-2

En definitiva, el fenómeno de las migraciones clandestinas seguirá siendo una asignatura pendiente en las relaciones interestatales mientras perduren las causas que lo origina. El problema no esta confinado entre los países que sufren directamente del fenómeno (de destino y de origen de la inmigración): es de todos, y la solución hay que encontrarla entre todos.

\section{CARACTERÍSTICAS GENERALES DE LOS INMIGRANTES}

La evolución reciente de las migraciones esta marcada por la aparición de nuevas tipologías migratorias. Los cambios observados se están manifestando en las características siguientes:

- Procedencia: antes la gente venia principalmente de la ciudad, muy pocos eran los que procedían directamente del campo. La primera emigración era del campo a la ciudad, era una emigración interna al país. Además los que emigraban no solían ser los más pobres. Actualmente, son más los rurales o habitantes de pequeña aldeas los que emigran.

“(...) existe una red que recluta generalmente en el medio rural.” D-3

Los candidatos son originarios no solo de Marruecos, también de otros países del Magreb o de África subsahariana. A veces tienen que atravesar varios países para llegar al Estrecho, exceptuando el caso marroquí. Posteriormente intentan acceder a España.

Desde el año 2002, las migraciones por el Estrecho de origen marroquí esta retrocediendo, mientras que la que procede de los países 
subsaharianos esta en constante aumento (en el 2004 se duplicado esta tendencia, según datos del Ministerio del Interior marroquí sobre las intercepciones de inmigrantes).

- Motivación: ya no son solamente las motivaciones económicas las que empuja masivamente a la gente a buscarse una vida mejor, las razones pueden ser de otra índole como huir de conflictos armados o de un clima social hostil o por efecto del mimetismo (copiar al pariente o vecino que le ha ido mejor en Europa).

"En el caso de Marruecos en particular no existe una explicación satisfactoria para explicar las razones que empujan a emigrar, no hay que caer en generalidades, y cada colectivo de inmigrantes debe ser analizado en función del lugar que ocupa en su sociedad." D-9

"Se ha visto emigrar a licenciados, funcionarios, gente con un empleo, una tienda (es decir un comercio)." D-3

- Género: en un principio, los emigrantes presentaban un perfil casi exclusivamente masculino, los movimientos migratorios se están transformando en mixtos. Cada vez hay más mujeres que intentan la aventura legal o ilegalmente.

"Hoy en día hay muchas mujeres que no dudan en ofrecer dinero para llegar a España." D-6

"El fenómeno va en aumento porque en los países del Sur, la mujer va cada vez mas adquiriendo auto estima y emancipación." D-10

- Edad: cada vez son más los jóvenes y menores (12-15 años) no acompañados que emigran clandestinamente sobre todo a España. Lo hacen escondiéndose en coches, autocares, contenedores, camiones,... a menudo con la complicidad y el apoyo de los padres. Muchos jóvenes desamparados rondan por el puerto de Tánger con la esperanza de encontrar el modo de cruzar el Estrecho.

"Al principio eran niños que habían abandonado sus hogares, o huérfanos. Están en todas las grandes ciudades. En Tánger el problema es mas grave porque existe la posibilidad de marcharse. Intentan esconderse en los contenedores, ... durante la noche.” D-3

"Los menores (...) han perdido la esperanza en el entorno y teniendo conocimiento de los medios y nivel de vida en la otra orilla se aventuran." D-11 
- Nivel de instrucción: antes analfabetos, hoy en día son cada vez más instruidos (bachiller y universitarios) y con una formación profesional cada vez mas especializada (técnicos o ingenieros). En el caso de Marruecos, se trata de jóvenes diplomados que, frustrados por las nulas perspectivas de encontrar trabajo en su país, optan por buscar la inmigración legal o ilegal para salir del túnel del paro.

"En mi región, los candidatos a la inmigración provienen de la alta montaña. Han pasado por la escuela y han fracasado, lo que significa que no es el pastor que se va pero alguien con un cierto nivel escolar." D-1

\section{EVOLUCIÓN RECIENTE DE LOS FLUJOS MIGRATORIOS}

Antes las rutas migratorias emprendían exclusivamente el paso por el Estrecho de Gibraltar porque representaba un recorrido fácil y corto que utilizaba pequeñas pateras con capacidad media de 30 inmigrantes (aunque a menudo se sobrecargaban). Este paso hoy en día se va cerrando por la actuación combinada de las autoridades marroquíes y españolas. Lo que conduce a los barqueros, dedicados al tráfico ilegal de personas de origen subsahariano, a buscar otras estrategias y otros recorridos que utilizan cayucos y van desde Nouadhibou (Mauritania) hasta Trípoli (Libia), pasando por Argelia o Túnez con destino a Canarias o Italia. Estas nuevas rutas migratorias son de largo recorrido y mucho más peligrosas.

Sin embargo, estos recorridos no son los que más alimentan los flujos migratorios, aunque sin duda los más mediatizados por los dramas que engendran (representan el 5\% del flujo total de inmigrantes). El grueso de la inmigración utiliza los aeropuertos y los Pirineos para entrar en España (representan el 95\%).

Los datos mas recientes del fenómeno migratorio hacen previsible que los movimientos migratorios se mantengan y que la necesidad en trabajadores en algunos sectores siga aumentando en los próximos años. Este crecimiento de la presión migratoria supone, al mismo tiempo, un crecimiento de los flujos clandestinos que utilizan las redes de trafico de personas para los que España no solo es un destino sino también un lugar de transito.

“Actualmente esta comprobado que más del 95\% de la inmigración en España entra por los Pirineos y el aeropuerto de Barajas y apenas un 5\% es la que procede de África en pateras o cayucos. Eso son datos conocidos y trabajados por distintos sociólogos de diferentes partes de España y también por profesores de las Universidades españolas concretamente de la ciudad de Madrid sobre la inmigración marroquí." D-9 
"España constituye para ellos un primer destino. Saben que es un país acogedor y que pueden más o menos encontrar empleo, pero no es una regla porque una vez bien establecidos pretenden alcanzar otros países (europeos)." D-11

\section{POSIBLES SOLUCIONES A LA INMIGRACIÓN}

Los movimientos migratorios plantean nuevos desafíos en las relaciones internacionales de los países enfrentados a este fenómeno. La problemática que suscita exige una nueva visión de su incidencia sobre las economías, las sociedades y las políticas de los países de acogida y de origen. Es imprescindible realizar una revisión de la percepción y del papel que desempeñan los emigrantes como factor de desarrollo.

La cuestión crucial del fenómeno de las migraciones es como resolver el problema de la inmigración ilegal. La repuesta a esta pregunta según los actores de nuestra encuesta pasa necesariamente por una reflexión profunda y una verdadera cooperación para el desarrollo entre Europa y África. Mientras siga existiendo una enorme fractura económica y social entre una Europa opulenta y una África de miseria y de pobreza, seguirán existiendo los candidatos dispuestos a todo con tal de buscarse la vida en otro sitio. Europa ${ }^{5}$ tiene que considerar como socios a los países emisores de una inmigración no deseada por ella, y buscar conjuntamente los mecanismos y las políticas que les permita sentar las bases de una economía basada en la innovación, la investigación y el desarrollo tecnológico, único gaje para un desarrollo humano sostenible.

Los países africanos tienen una gran responsabilidad en la desesperación social de sus populaciones, desesperación que les empuja a arriesgar la vida por intentar alcanzar la otra orilla. Estas odiseas suicidarías tienen que cesar y para lograrlo los países africanos tienen la responsabilidad y la obligación de promover políticas que permitan crear las condiciones mínimas para una vida decente.

En el caso de Marruecos existe una voluntad de compromiso con la Unión Europea para buscar soluciones al problema de la inmigración ilegal. El país magrebí está colaborando activamente para frenar el flujo de inmigrantes subsaharianos (principalmente) que utilizan su territorio para sus proyectos migratorios. El acuerdo está funcionando bastante bien por el momento.

Sin embargo, a pesar de los cambios importantes que se están produciendo en el país a todos los niveles, se consideran insuficientes según algunos, demasiado lentos según otros, y no se dibuja en el horizonte una mejora en las perspectivas de futuro para una gran parte de la población marroquí joven y frustrada.

"El fenómeno perdurará. La necesitad esta presente. Hay los que buscan unas condiciones de acceso legales y los que lo hacen de manera ilegal, cuando no les es posible legalmente. Las perspectivas demográficas y económicas incitan a los países emisores a proveer mano de obra." D-3 


\section{LA VOZ DE LOS EXPERTOS}

En este epígrafe resumimos algunas ideas clave que constituyen lo que llamaríamos la "voz de los expertos" y que representan lo que piensan algunos expertos sobre el fenómeno de las migraciones.

"Marruecos reúne las típicas características de un país $p u s h^{6}$."

El perfil actual de la sociedad marroquí cuadra completamente con los parámetros establecidos por los demógrafos para definir una sociedad push, principalmente:

- Desequilibrios económicos; destacando notoriamente la inadecuación de los salarios de la mayor parte de la población a los precios, un elevado desempleo ( $19 \%$ de la población activa), así como una enorme dependencia de la agricultura de la climatología y una economía sumergida imposible de controlar.

- Profunda estratificación social, con enormes brechas sociales implicadas por el hecho de que el $20 \%$ de la población gestione el $80 \%$ de los recursos.

- Pirámide de población joven, con altas tasas de natalidad y mortalidad, así como escasas medidas de contracepción y un importante predominio cultural de la familia numerosa sobre todo entre la población rural $(45 \%$ de la población total).

- Escasez de coberturas sociales del sistema gubernamental. Destacando, especialmente la inexistencia del subsidio de desempleo.

"Su ubicación geográfica y su carácter fronterizo le colocan en una situación de continua tensión sociopolítica ante el problema de las migraciones."

Dadas las actuales condiciones de vida de los países subsaharianos, tal y como delata la muestra del estudio (véase perfil 9), los flujos migratorios continuarán hacia el norte de Marruecos. Estos, unidos a los nacionales, generan una enorme demanda migratoria que desborda las posibilidades legales y aumenta la oferta de los negocios ilegales (mafias). Las rutas alternativas, como la generada entre Mauritania o Argelia y el sur de Marruecos solo contribuyen a diversificar las alternativas.

Estas circunstancias colocan a la Unión Europea en el rol de "policía", con el que el gobierno marroquí debe bregar continuamente. Si bien, la colaboración con la Unión Europea en el control de la emigración se ha convertido en una importante contraprestación en las negociaciones con el gigante del norte. 
Marruecos trata de usarla como moneda de cambio para lograr más ayuda económica y mejor trato comercial.

"La emigración es un fenómeno transocial, afecta a todas las clases sociales de Marruecos."

La tendencia afecta a todos los colectivos sociales marroquíes, si bien cada clase social da lugar a circunstancias muy distintas con perfiles migratorios particulares. La amplia gama que ofrecen los contextos sociales del emigrante va desde el universitario que busca mejorar su calificación en el empleo que puede ofrecerle Europa, hasta el joven sin estudios que se lanza a las vías ilegales a la desesperada, tal y como ha delatado el trabajo de campo. En el epígrafe posterior matizaremos estos perfiles.

"El futuro del norte de Marruecos pasa por la inversión de la UE."

Dadas las actuales dificultades que soporta la economía marroquí, resulta impensable reparar todas las brechas existentes sin la colaboración del vecino del otro lado del Mediterráneo. Su enorme dependencia, como hemos avanzado antes, de la agricultura y la economía sumergida, así como la inexistencia de un tejido industrial sólido reclaman la aportación de una Europa que es también actor interesado en el equilibro de su zona geográfica de mayor influencia. Nuestro estudio delata las dificultades de los afectados para cubrir sus necesidades en casa: el argumento esencial para salir del país y, por lo tanto, el germen del problema internacional.

"La mejora de las políticas sociales de Marruecos es urgente."

Con la coronación del Rey Mohammed VI comenzaron a soplar vientos de optimismo en algunos sectores de la población. El Rey está considerado por los analistas como más progresista que sus antecesores y comprometido en las reformas sociales, tal y como veremos en estas conclusiones. Aunque las estadísticas empiezan a delatar algunas mejoras, los efectos de estas inversiones son realmente lentos. La urgencia de las medidas, para equilibrar los salarios con los precios y el acceso de los jóvenes a un primer empleo digno, es evidente. Estas mejoras no son solo necesarias para moderar las conductas migratorias, también lo son para mejorar el equilibrio del país en su conjunto.

"La mujer tiene un perfil migratorio notoriamente diferente al del hombre."

La sociedad marroquí, en la línea de los países musulmanes, marca estrictamente las diferencias entre los roles de género. Esta distancia queda también 
notoriamente marcada en los roles migratorios. De entrada, como veremos en páginas posteriores, el clima familiar empuja mucho más a la emigración a los varones, por detrimento de las chicas. A pesar de ello, las dificultades que atraviesa el país han presionado cada vez más a las mujeres a marcharse.

Mientras entre los hombres abundan las vías ilegales para cruzar el Estrecho, las mujeres son más partidarias del "matrimonio en blanco", los procesos de reagrupación familiar o los contratos de trabajo. La emigración de la mujer está generalmente vinculada a la de su grupo familiar, mientras el hombre es más propenso a lanzarse a la aventura individualmente. Recordemos la importancia que tiene en la cultura musulmana que la mujer dedique horas al cuidado de su casa y su familia, mientras que las expectativas sobre el hombre, implican que sea un buen proveedor de recursos al hogar (que frecuentemente llegan en forma de remesas).

"El menor inmigrante: nuevo protagonista en los procesos migratorios."

En los movimientos migratorios entre Marruecos y España, el menor no acompañado aparece como el nuevo protagonista.

Es el "último eslabón" de una compleja y preocupante realidad social marroquí relacionada con la desprotección social, una creciente feminización de la inmigración, una tasa de abandono escolar elevada entre los jóvenes, una incorporación precoz al mundo laboral en condiciones precarias. Este panorama es el reflejo de la ausencia de una política integral de protección de la infancia, a pesar de los avances sociales ${ }^{7}$. El menor ve en la inmigración la única salida para ganarse la vida. Esta idea es afianzada por la falta de perspectivas de futuro de sus mayores -hayan estudiado o no-, y por la imagen de éxito social que transmiten los inmigrantes que regresan de vacaciones al país.

"La fuerte influencia occidental obliga a un acercamiento socioeconómico."

Marruecos está clasificado, dentro del contexto islámico, como uno de los países más progresistas y liberales. Sus líderes políticos y espirituales son algo más moderados en las interpretaciones del Corán. En esta configuración ideológica ha tenido una notable influencia su vecindad con Europa, así como su reciente pasado colonial. Por otra parte, el país se encuentra en una situación de fuerte contagio de las sociedades de consumo occidentales, en la que los medios de comunicación han actuado como principal agente trasmisor. Esta histórica aculturación ha generado una importante sinergia en lo político y económico, claramente reflejada en la vertebración de sus instituciones, parcialmente occidentalizadas.

Estas circunstancias implican que la generación de necesidades socioeconómicas sea mucho más intensa que en otros países en vías de desarrollo.

"El asociacionismo: motor de progreso y de paz." 8 
Las asociaciones y ONG's pro inmigrantes o de inmigrantes no están desempeñando el papel que les corresponde principalmente por dos razones: el Estado no ocupa el rol de "agente federador" y las asociaciones, desgraciadamente muchas de estas no tienen un tejido social detrás, se instalan en una "rutina" que les aparta de sus objetivos principales.

El rol del Estado en materia de migraciones tiene que enmarcarse, no solamente en un respeto escrupuloso de la diversidad, que representa una riqueza en el tejido social del país - no debe perjudicar a la afirmación de los diferentes componentes generacionales, nacionales, culturales,... - pero también tiene que guiar, incentivar, controlar y coordinar las acciones de las asociaciones con tejido social fuerte que reciben subvenciones publicas.

Muchas asociaciones se han instalado confortablemente en lo que podríamos llamar una "rutina tranquila" que les transforma en estructuras de autogestión que dan prioridad a acciones emblemáticas con gran impacto mediático (festivales de inmigrantes, fiestas de gastronomía o culturales,...), dejando de lado aspectos que deberían movilizar mas sus recursos. Con excepción del tema de las regularizaciones de los inmigrantes en situación irregular y de los candidatos al estatuto de refugiado, sus acciones están muy limitadas sobre las cuestiones de discriminación y exclusión social y económica que afecta a los inmigrantes, las dificultades lingüísticas y el fracaso escolar de los hijos de la inmigración, la violencia hacia las mujeres o los niños dentro del núcleo familiar, la prevención del SIDA, la lucha contra la utilización de substancias nocivas para la salud (en particular para los jóvenes),... temas sobre los cuales las asociaciones de base deberían convertirse en intermediarios o mediadores privilegiados del Estado y de las Comunas.

\section{CONCLUSIONES Y PERSPECTIVAS DE FUTURO EN EL ÁMBITO DEL MEDITERRÁNEO}

El emigrante en Marruecos está tomando, cada vez más, un "perfil transocial". Los perfiles migratorios ${ }^{9}$ se han extendido muy notoriamente a las clases medias y altas. En este fenómeno ha resultado determinante el "efecto llamada" generado por personas del mismo nivel social que se han integrado en Europa logrando importantes progresos en sus carreras profesionales y en sus estudios. Estas circunstancias delatan las enormes deficiencias aún existentes en Marruecos en formación y empleo ${ }^{10}$, a pesar de los esfuerzos recientes del Rey Mohamed VI.

La Unión Europea continuará siendo protagonista en el debate sobre la emigración y deberá "tomar parte activa en el desarrollo del norte de África", si realmente pretende moderar los flujos migratorios actuales. 
El gobierno de los veinticinco ha mostrado en su último consejo del mes de octubre 2006, en la ciudad finlandesa de Lahtí, su propósito de poner punto y final a las regularizaciones masivas, con un contundente "tirón de orejas" al último Estado que apostó por ellas: el español ${ }^{11}$.

Entre las últimas propuestas del Presidente del Gobierno, José Luís Rodríguez Zapatero, en la reunión del Consejo Europeo del 20 de octubre de 2006, asumiendo el liderazgo de la UE en materia de gestión comunitaria de los crecientes flujos migratorios, propuso la creación de agencias de empleo europeas en terceros países para compensar el freno en las políticas regularizadoras.

Cataluña fue precursora, en este sentido, incentivando a las empresas catalanas para abrir despachos de asesoramiento o de contratación directa en Marruecos ${ }^{12}$, o con la apertura de una oficina de empleo en Tánger ${ }^{13}$. Esta política esta teniendo un éxito moderado hasta el momento con respeto a la disminución de la presión migratoria.

Estas acciones no serán suficientes, y son sólo un esbozo de la política que los 25 deberán aplicar a corto plazo. Pero, al menos, es una propuesta esperanzadora que nos trae el recuerdo de tiempos pasados en las migraciones europeas, en los que la mayoría de los trabajadores del sur de Europa que llegaban a países receptores como Alemania y Suiza, lo hacía con un contrato de trabajo bajo el brazo. En las décadas de los 50 y 60, la política migratoria en Europa acabó beneficiando tanto a los países "de acogida como a los de origen". De esta forma el mercado de trabajo europeo se estabilizó y el Sur contribuyó a la "dinamización" industrial del Norte.

En el futuro del Mediterráneo será determinante enfocar las políticas de gestión de las migraciones conforme a las siguientes bases:

Enfatizar en la idea de la migración como intercambio, motor de progreso y de paz.

Para afrontar el futuro de las políticas migratorias europeas resulta esencial asumir que los beneficios de las migraciones no sólo se dan en los países exportadores de mano de obra ${ }^{14}$. Históricamente estos beneficios se hacen también muy palpables en los países receptores ${ }^{15}$. El pasado reciente de los países europeos así lo demuestra. No obstante, debemos plantear las migraciones como un intercambio que beneficia a ambos bloques, genera progreso y estabilidad, si bien debemos entender que la recompensa no es la misma para unos y otros. En este sentido, Europa debe ingeniarse en conjugar los beneficios de las migraciones con algunos efectos perversos.

Los estudios socioeconómicos, realizados por diversos entes, demuestran el constante aumento de la demanda de mano de obra en los países industrializados de Europa. 
Esta circunstancia, unida a las carencias en la oferta de mano de obra en el norte de África, implica que tendremos que seguir conectándola con los flujos. La población marroquí ${ }^{16}$, al igual que la mayor parte de África está soportando condiciones de infrasalario. Sin embargo, el tejido empresarial europeo aún presenta algunas carencias para cubrir algunos puestos, especialmente, en el sector servicios y la agricultura. Además, en caso de no haber contado con la mano de obra emigrante de los últimos 20 años, los salarios hubieran subido hasta un punto difícilmente soportable para las empresas y se hubiera complicado la existencia al consumidor por la subida del precio final. La opinión pública europea debe superar los momentos de crisis económica y de empleo que les hacen mirar con recelo a los emigrantes. Su mano de obra ha sido esencial en otros momentos difíciles.

"Por otra parte, la revitalización demográfica de países europeos -que contaban con pirámides de población envejecidas- se está logrando gracias al apoyo "natalista" de los países del sur".

Este ha sido el caso de los países nórdicos, Francia, Reino Unido, Alemania, Holanda, Italia y, posteriormente, España. Los demógrafos europeos encendieron la luz roja sobre el problema del envejecimiento en la década de los $80^{17}$. Los rasgos sociológicos de estas sociedades les impedían levantar su población por si solas. Sin duda, la inmigración ha sido determinante para que un país como España ${ }^{18}$ pasara en 2005 los 44 millones de habitantes y -lo que resulta aún más importante- se haya incrementado la tasa de natalidad y accedan a la educación infantil cohortes mucho más numerosas que hace dos décadas.

Comparativamente a la evolución de la demográfica registrada en Europa, que conocerá un crecimiento en el horizonte 2025 a penas de un $4 \%$ pasando a rozar los 400 millones de habitantes, el de Marruecos alcanzara cerca del 35\%. Este crecimiento es tal que la población de Marruecos se equiparara a la población española en el año 2025, actualmente la población de España es superior un 35\%. El significado de esta situación es que la presión demográfica que experimenta Marruecos seguirá siendo un factor generador de la inmigración puesto que el mercado de trabajo, con las mismas condiciones que existen hoy, no podrá absorber el incremento importante del flujo de mano de obra (cada vez más formada y con un nivel de formación creciente).

"No todos pueden trabajar al otro lado del Estrecho" por lo que hay que equilibrar los niveles de renta y las prestaciones sociales a ambas orillas del Mediterráneo.

Las mismas razones demográficas y económicas, anteriormente explicadas, obligan a la vieja Europa a poner sus límites al fenómeno migratorio. La Unión Europea tiene cada vez más clara la importancia de la emigración africana, en dos líneas opuestas: hay que detener la inmigración clandestina, pero también hay que dar entrada 
a un contingente de personas totalmente necesarias para mantener el crecimiento actual. Por ahora no existe una política común, cada país actúa por su cuenta. De momento se dedican a controlar lo mejor posible sus fronteras y a exigir a Libia, Marruecos y Argelia el control de la migración.

Esta claro que no hay sitio para todos, pero si debemos identificar el espacio Mediterráneo como un ecosistema político que hay que mantener en equilibrio: todo está demasiado cerca como para tratar de verlo de otra forma. Las civilizaciones antiguas que lucharon por el control del Mare Nostrum siempre observaron la necesidad de tratarlo como un área geográfica interdependiente. La Unión Europea, por intereses propios y ajenos, "debe potenciar el desarrollo económico del Norte de África” aumentando, aún más, sus coberturas en cooperación.

Asfixiar y desalentar la emigración ilegal y al mismo tiempo actuar sobre las causas profundas que la engendran y la sustentan.

Los países de la Unión Europea deben ser estrictos en el control de los ilegales y lograr la cooperación de los gobiernos africanos para evitar que proliferen las redes que desestabilizan el ecosistema social y, en algunos casos, ponen en peligro a sus ciudadanos. Si bien, la labor fundamental de los políticos de ambos continentes está en canalizar estos intereses hacia nuevas oportunidades de emigración legal, u ofrecer alternativas solventes ${ }^{19}$ en los destinos de origen. Las regularizaciones masivas, tan discutidas en los tiempos que corren, sólo solucionan el problema de algunos de los ilegales ya desplazados, pero implican un aumento del "efecto llamada" en los países de origen, o alimentando el papel de las mafias y generando los riesgos ya comentados.

Hay que actuar sobre las causas que generan el fenómeno de la inmigración ilegal, en el caso de la migración marroquí, se enmarca en una problemática global que interpela a los gobiernos de Marruecos como a los de los países de la Unión Europea.

En primer lugar, hay que romper con los esquemas vinculados al síndrome de la seguridad y de los riesgos relacionados con la inmigración y apostar por un enfoque preventivo orientado hacia una política realista porque basada en una necesidad.

Seria interesante que la política de cooperación ayudara a la estabilización territorial de la población, porque es una manera de frenar la emigración interna y así frenar los flujos migratorios hacia Europa. Para ello se necesita programas de cooperación que dinamicen la economía del país de origen con el fin de crear empleo y en los cuales haya repercusión a efectos multiplicador.

Insuficiencia de la ayuda europea e inadecuación con respecto a las necesidades de los países emisores de la inmigración. 
Existe un sentimiento generalizado entre la población entrevistada de que las políticas europeas, o españolas en materia de cooperación y de apoyo al desarrollo no van encaminadas hacia un desarrollo total de los países emisores de la inmigración, y que sirven mas sus propios interés.

Lo más urgente, según hemos sacado de las entrevistas, es hacer un inventario de la memoria y potenciar el intercambio de tecnología, creando centros mixtos para la valorización y revalorización de las culturas de ambos países y para la promoción de la investigación científica. El objetivo a largo plazo es edificar un verdadero proyecto de sociedad con todos sus componentes y no limitarse a solo algunos aspectos limitativos de una $\mathrm{u}$ otra cultura.

La deuda histórica de la colonización no debe servir para excusar la inoperancia de los gobiernos africanos para contrarrestar el problema.

Europa ha sido un antiguo colonizador en los países africanos. Con el tiempo, estos han accedido a la independencia política pero siguen dependiendo de Europa a nivel económico y social. Es por ello que Europa debe tomar en consideración el pasado de su relación con África, y apostar por estrategias socio económicas que permitan dar a los países africanos la posibilidad de mejorar sus realidades.

Los países africanos colaboran en mayor o menor medida en la limitación de la inmigración ilegal, lo cual da pie a un mercadeo de subcontrata en el que se juegan derechos importantes de asilo e inmigración: una externalización de la crisis de las corrientes humanas. Libia dijo el pasado año que no podía ser el guardacostas de Europa: imposible bloquear ella sola a millones de personas que quieren ir a Europa. Marruecos se queja de las fuertes exigencias en este tema, sin que haya una compensación económica que cubra el despliegue de fuerzas realizado. Acusa a los medios europeos de parcialidad: no mencionan para nada la falta de colaboración de Argelia, por donde pasan más del $80 \%$ de los emigrantes subsaharianos.

En el caso de Marruecos, la diversidad de recursos a explotar de los que goza el país invita a aumentar las exigencias a sus administradores. Las circunstancias privan a muchos del derecho a ganarse la vida dignamente en el pueblo que les vio nacer. Ante todo, las políticas sociales del presente y el futuro deberán priorizar el acceso a la formación y al empleo de los más jóvenes, o sea, la cantera de la emigración.

Desde 1995 hasta la actualidad hay cambios importantes en todos los sectores de Marruecos pero no suficientes y de resultados poco visibles a corto plazo. Marruecos es un país en construcción.

Otra cosa es que Marruecos tiene que hacer el esfuerzo de dar otra imagen más real del país y combatir la imagen estereotipada negativa que tiene en el exterior. 


\section{NOTAS}

${ }^{1}$ Entrevistas a 22 expertos españoles y marroquíes en temas de inmigración (codificados de D1 a D22).

${ }^{2}$ Telediario de TVE Internacional del miércoles 14 de noviembre de 2006.

${ }^{3}$ Cadena de televisión ARTE, jueves 15 de noviembre de 2006

4 «Los inmigrantes han contribuido a la creación del 50\% de los nuevos empleos desde el año 2001 e ingresan 23 mil millones de euros por año a Hacienda, o sea 6,6\% del presupuesto del Estado. Esta contribución seguirá creciendo en los próximos años." Según un estudio hecho publico a mediados del mes de noviembre 2006 y dirigido por Miguel Sebastián, principal consejero económico del jefe del Gobierno, José Luís Rodríguez Zapatero.

${ }^{5}$ « Con la ayuda de la política de cohesión de la UE, España a realizado importantes avances en la puesta en pie de una infraestructura propicia al desarrollo », Danuta Hübner, comisario a cargo de la política regional en su conferencia madrileña del 26/10/2006 titulada "España y la Unión Europea: Edificar juntos la economía del conocimiento".

${ }^{6}$ Teoría formulada por el demógrafo E. G. Ravenstein a finales del siglo XIX (1885 y 1889). A pesar de las críticas recibidas, por sus pretensiones ahistoricistas entre otras cuestiones (R. Cohen, 1987: 34-35; A. R. Zolberg, 1989: 403-405; S. Castles y J. M. Miller, 1993: 19-21), este estudio precursor sigue citándose entre los economistas y los demógrafos, y continúa orientando numerosas políticas, quienes suelen hablar en un lenguaje mercantilista de control de flujos y gestión de stocks.

Fenómeno demográfico Push - Pull: se entiende por un país "push" aquel que reúne las condiciones socioeconómicas que provocan, de forma natural, la salida de parte de su población en búsqueda de mejores condiciones de vida. Por otra parte, los países "pull" son los que reúnen las condiciones propias para atraer población de otros lugares con peor fortuna, como son el acercamiento al pleno empleo y las coberturas sociales.

${ }^{7}$ La Mudawana (2004), el Código del Trabajo (2003), la Ley 02-03 (2003) sobre inmigración e emigración irregulares (2003),...

${ }^{8}$ Katrien de Muynck (febrero 2006), artículo titulado "El caso francés: la primera política oficial de codesarrollo", basado en el informe de Sami Nair. (www.codesarrollo-cideal.org).

9 “...La diversidad de perfiles migratorios por su procedencia, destino, edad, género, nivel de instrucción hace del fenómeno migratorio un proceso complejo que no responde a un único modelo de comportamiento." en EGEA, C., NIETO, J. A., RODRÍGUEZ, V., JIMÉNEZ, F. "La inmigración actual en Andalucía (1997-2001)". Geo Crítica / Scripta Nova. Revista electrónica de geografía y ciencias sociales. Barcelona: Universidad de Barcelona, 1 de julio de 2005, vol. IX, núm. 192. http://www.ub.es/geocrit/sn/sn-192.htm [ISSN: 1138-9788].

${ }^{10}$ Véase informe "Estudio sobre la situación de las mujeres a ambos lados del Estrecho de Gibraltar" realizado por Gema González Ferrera, Jamal Benamar y otros, editado por el Instituto Andaluz de la Mujer, ISBN 84-7921-138-5, 2006.

${ }^{11}$ La delegación española recordaba a sus socios en Lahti que esa 'legalización' se hizo antes de que se hubiera esbozado siquiera la creación de un sistema de información mutua entre los países de la UE. Un mecanismo que todavía no se ha aprobado oficialmente.

${ }^{12}$ Europa Press (04/01/2006): "Garrigues abre un despacho en Casablanca para asesorar las empresas españolas que inviertan en Marruecos". 
13 Servei d'Ocupació de Catalunya (SOC), para contratar trabajadores marroquíes que quieran venir a Cataluña y ayudar a las empresas catalanas erradicadas en tierra marroquí a encontrar mano de obra, que en su mayoría son del sector textil. Abrió sus puertas el pasado 2 de mayo y tuvo que cerrar a las dos semanas de su inauguración ante el alud de demandas venidos de toda parte del país.

${ }^{14}$ Marruecos es uno de los países del mundo que mas depende de las remesas de sus inmigrantes, estas representan cerca del 10\% del PIB (datos de la Oficina de Cambios, 2003)

${ }^{15}$ España ingresa casi el doble de lo que gasta por los inmigrantes según Rosa Aparicio Gómez, "El impacto económico de la inmigración: costos para el Estado y movimiento de consumo y salarios", 2000.

${ }^{16}$ En el caso de Marruecos (Fuente: Dirección de la Estadística, 2004) hay que destacar los desequilibrios siguientes: una renta per capita 17 veces inferior a la de España, una economía que depende del sector primario muy inestable debido a los cambios climáticos, el paro que aumenta entre las mujeres y la población joven (mas del $60 \%$ de la población activa en paro tiene menos de 30 años), según el umbral de la pobreza (fijado por el Banco Mundial a 1euro por persona y día) cerca de $19 \%$ de la población marroquí es pobre, el salario mínimo es cuatro veces inferior al de los países europeos.

17 Según los redactores del "libro azul" (Grenis, M. y Battis, M. , "El libro Azul", Económica, 1989) : “de los 170 millones de ribereños de aquí al año 2025, 68\% habrán nacido en un país árabe, $22 \%$ en Turquía y solamente 10\% en Europa”.

${ }_{18}$ Con relación al total de nacimientos en España, los de madre extranjera supusieron en el año 2005 el 15\% del total, frente al 12,2\% del año 2003. Las que más hijos tuvieron fueron las marroquíes con el $20,8 \%$ del total de nacimientos de madre extranjera (según el INE: Movimiento Natural de Población, Datos provisionales 2005).

${ }_{19}$ Moratinos ha hablado de la cumbre sobre inmigración y desarrollo que tuvo lugar en Rabat en julio pasado y que reunió 57 países de África y Europa “como un nuevo modelo de abordar el fenómeno migratorio más pragmático y eficaz, a partir de la corresponsabilidad de los países de origen, de tránsito y de destino" (www.elpais.es, 10/07/2006).

A pesar de las buenas intenciones manifestadas en esta cumbre, preocupa el echo que todo se quede en una mera declaración de buenas intenciones, en la medida que no se han asumido compromisos concretos con calendarización ("En definitiva, mas de lo mismo", www.sosracismo.es ).

\section{BIBLIOGRAFIA}

AKELLAL, A. (1999): "Les motivations historiques et sociales de l'émigration marocaine", in L'émigration marocaine, Rabat, Publications de l'Académie du Royaume du Maroc.

AUBRY, M. (coord.) (2006): Immigration, comprendre, construire, La Tour d'Aigues, Ed. de l'Aube

AZURMENDI, M. (2003): Todos somos nosotros, Madrid, Taurus.

CABRERA, M. (2005): Acercamiento al menor inmigrante marroquí, Sevilla, Dirección General de Coordinación de Políticas Migratorias, Junta de Andalucía. 
CHECA, F. CHECA J.C. y ARJONA A. (eds.) (2000): Convivencia entre culturas: El fenómeno migratorio en España, Sevilla, Ediciones de Andalucía, S.L.

COLECCIÓN Alternatives Sud (2004): Genèse et enjeux des migrations internationales, Paris.

DÍEZ NICOLÁS, J. (1999): Los españoles y la inmigración, Madrid, IMSERSO.

EL MOUHOUB, M. (2005): Les nouvelles migrations: un enjeu Nord-Sud de la mondialisation, Paris, Universalis.

GARCÍA-CALABRÉS COBO, F. (2004): La extranjera, estudio de la inmigración femenina en España, Córdoba, Dirección General de Coordinación de Políticas Migratorias, Junta de Andalucía.

GIMÉNEZ, C., ACOSTA, A. y AUBARELL, G. (2005): Migraciones y desarrollo. Estudio de dos casos particulares: Ecuador y Marruecos, Madrid, CECOD.

GÓMEZ SOTA, F. (2004): Imágenes cruzadas. Percepciones españolas de la inmigración marroqui en la Comunidad de Madrid, Madrid, UNED.

GONZÁLEZ FERRERA, G. y Col. (BENAMAR J.) (2006): Estudio sobre la situación de las mujeres a ambos lados del Estrecho de Gibraltar, Sevilla, Instituto Andaluz de la Mujer, ISBN 84-7921-138-5.

HOLGADO MOLINA, M. (2001): Relaciones comerciales entre España y Marruecos: 1956-199, Granada, Universidad de Granada.

LA COMBA, J. (2004): Migraciones y desarrollo en Marruecos, Madrid, La Catarata.

LARRAMENDI, M.H. de y NÚÑEZ VILLAVERDE, J. A. (1996): La política exterior y de cooperación de España en el Magreb (1982-1995), Madrid, IUDC-La Catarata.

MAHÍA, R. (2005): El efecto de la inmigración Económica en el mercado español: Cifras básicas y reflexiones analíticas", Madrid, Universidad Autónoma de Madrid.

MARTÍNEZ CARRERAS, J. U. (2000): Relaciones entre España y Marruecos en el siglo $X X$, Madrid, AEA.

MARTÍNEZ VEIGA, U. (2001): El Ejido. Discriminación, exclusión social y racismo, Madrid, La Catarata.

MÉDICOS SIN FRONTERAS (2005): Informe sobre la inmigración de origen subsahariano en situación irregular en Marruecos, MDF-E.

PAJARES, M. (1998): La inmigración en España. Retos y propuestas, Barcelona, Icaria.

I PLAN INTEGRAL PARA LA INMIGRACIÓN EN ANDALUCÍA.2001-2004 (2005). Sevilla, Dirección General de Coordinación de Políticas Migratorias, Junta de Andalucía.

ROMERO BARTUMEUS, L. (2003): El estrecho en la política de seguridad española del siglo $X X$, Algeciras, APCG.

RUÍZ OLABUÉNAGA, J. I. (1999): Los inmigrantes irregulares en España, Bilbao, Universidad de Deusto.

SAMI, N. (2000): El peaje de la vida, Madrid, Aguilar/ Ediciones El País. SOREL, A. (2000): Las voces del Estrecho, Barcelona, Muchnik Editores. 
